Acta Botanica Brasilica - 31(2): 313-318. April-June 2017. doi: 10.1590/0102-33062016abb438

\title{
Spore germination and young gametophyte development of the endemic Brazilian hornwort Notothylas vitalii Udar \& Singh (Notothyladaceae - Anthocerotophyta], with insights into sporeling evolution
}

\author{
Bárbara Azevedo Oliveira', Anna Flora de Novaes Pereira², Kátia Cavalcanti Pôrto ${ }^{3}$ \\ and Adaises Simone Maciel-Silva ${ }^{1 *}$
}

Received: December 9, 2016

Accepted: March 2, 2017

\begin{abstract}
Notothylas vitalii is an endemic Brazilian hornwort species, easily identified by the absence of pseudoelaters and columella, and the presence of yellow spores. Plant material was collected in Recife, Brazil, and the spores were sown onto Knop's medium, germinating after thirty days only with the presence of light. Germination occurred outside the exospore, and only after the walls had separated into three or four sections did a globose sporeling initiate its development. Following longitudinal and transversal divisions, the initial loose mass of cells became a thalloid gametophyte, subsequently developing into a rosette-like juvenile thallus with flattened lobes. Additional information concerning sporeling types in key genera of hornworts, such as Folioceros and Phymatoceros, will be crucial for inferring the possible ancestral type and the evolution of this trait among hornworts. Our study supports the necessity of supplementary studies on sporeling development, combined with morphological and phylogenetic investigations, to help elucidate the evolution of the Anthocerotophyta and their distribution patterns.
\end{abstract}

Keywords: bryophytes, exosporous germination, phylogeny, sporeling development, yellow spores

The earliest developmental stages of different bryophyte species can provide important sources of phylogenetic and evolutionary information (Nehira 1983; Mishler 1986; Duckett et al. 2004). Studies of spore germination and sporeling development patterns, for example, have been used to support the phylogenetic or systematic relationships of many bryophyte species among the liverworts Fossombronia cristula (Renzaglia \& Bartholomew 1985) and Monoclea gottschei (Bartholomew-Began \& Crandall-Stotler 1994), mosses Braunia secunda, Hedwigia ciliata, Hedwigidium integrifolium, Pseudobraunia californica, Rhacocarpus purpurascens (Luna 1990), and Dolichomitriopsis diversiformis (Liu et al. 2016), and hornworts, the genera Notothylas and Phaeoceros (Menéndez 1988).

\footnotetext{
${ }^{1}$ Departamento de Botânica, Universidade Federal de Minas Gerais, Av. Antônio Carlos, 6627, Pampulha, 31270-901, Belo Horizonte, MG, Brazil

${ }^{2}$ Universidade Federal do Vale do São Francisco, 64770-000, São Raimundo Nonato, PI, Brazil

${ }^{3}$ Departamento de Botânica, Universidade Federal de Pernambuco, 50372-970, Recife, PE, Brazil

* Corresponding author: adaisesmaciel@ufmg.br
} 
Sporeling development in the phylum Anthocerotophyta varies from either an initial globose or cylindrical protonema developing outside the exospore (spore wall), thus typifying exosporous germination, as in Anthoceros, Notothylas, Phaeoceros, and Megaceros, among others (Campbell 1895; Mehra \& Kachroo 1962; Renzaglia 1978; Nehira 1983; Wada et al. 1984; Herguido \& Ron 1989), to a multicellular protonema developing inside the exospore (endosporous germination), as in the epiphyte Dendroceros (Schuette \& Renzaglia 2010) and in Nothoceros renzagliensis (Villarreal et al. 2012).

The family Notothyladaceae currently includes the genera Notothylas, Phaeoceros, Paraphymatoceros, and Mesoceros (Stotler \& Crandall-Stotler 2005; Duff et al. 2007; Renzaglia et al. 2007; Renzaglia et al. 2008; Söderström et al. 2016), with Phaeoceros and Notothylas comprising the most species (ca. 56). Notothylas and Phaeoceros are considered sister groups (Menéndez 1988; Stech et al. 2003; Duff et al. 2004; 2007) and share characteristics such as yellow spores, similar germination patterns, and similar sporeling morphologies (Menéndez 1988). The germination patterns and sporeling morphologies of some of the species of this family are known, such as Notothylas orbicularis, $N$. levieri, $N$. javanica, N. flabellata, N. indica, Phaeoceros laevis, $P$. tenuis, and P. huebschmannii (Kachroo 1962; Renzaglia 1978; Mehra \& Nehira 1983; Menéndez 1988). The spores of the phylogenetically related genera Notothylas and Phaeoceros germinate outside the exospore, and their protonema develop into compact masses composed of only a few cells (Menéndez 1988; Cargill et al. 2005; Renzaglia et al. 2008).

Notothylas is a genus of ephemeral plants that grow on open soils as pioneer plants (Shaw \& Renzaglia 2004). They are very distinct hornworts, with reduced and horizontal sporophytes enclosed within involucres (Udar \& Singh 1981; Cargill et al. 2005; Chantanaorrapint 2015). Three Notothylas species are recognized in Brazil (N. breutelii, $N$. orbicularis, and N. vitalii); Notothylas vitalii is endemic to Brazil and has been recorded in the central-western, northern, northeastern, and southeastern regions of that country (Yano et al. 2011).

Notothylas vitalii is commonly encountered growing on garden soils and near plantations, generally appearing during rainy months and disappearing during the dry season (Martins et al. 1990). There are no dehiscence lines on the capsules of N. vitalii (Fig. 1A, B), and Udar \& Singh (1980) noted that its spores are usually dispersed by a transversal separation of the apical portion of the sporangium; pseudoelaters and columella are also absent (Udar \& Singh 1980; Martins et al. 1990; Gradstein \& Costa 2003). Benitez et al. (2012) reported N. vitalii for Ecuador as being characterized by the presence of pseudoelaters and longitudinal sporangium opening - but this suggests a misidentification, as those traits are descriptions of Notothylas orbicularis. This type of error often occurs because the descriptions of $N$. vitalii and $N$. orbicularis were inverted by Gradstein \& Costa (2003).

Even though N. vitalii is considered endemic to Brazil, it has characters that resemble Notothylas javanica, including the presence of sporangium without a special dehiscence line, the absence of pseudoelaters, a non-persistent/absent columella, and yellow spores (Stieperaere \& Matcham 2007; Chantanaorrapint 2015). Taxonomic studies will need to be undertaken, whoever, to confirm if $N$. vitalii might be $N$. javanica in South America.

To determine if the sporeling pattern observed in other species of Notothylas is maintained in the rather peculiar species $N$. vitalii, we examined its spore germination, sporeling development, and juvenile thallus. Our study likewise contributes to a better understanding of sporeling evolution among hornworts based on recent phylogenies and data on sporeling types available in the literature.

Plant material for the study was collected in September 2005 on the campus of the Federal University of Pernambuco (Recife, Pernambuco State, Brazil; $8^{\circ} 03^{\prime} 09.3^{\prime \prime}$ S, 34 57'11.7”W). In September 2005, fresh, mature sporophytes of Notothylas vitalii Udar \& Sigh were detached from the gametophytes, sterilized in $1.5 \%$ sodium hypochlorite for $5 \mathrm{~min}$, and subsequently rinsed with distilled water (Duckett et al. 2004). Forty sporangia were opened and the spores removed, homogenized, and spread onto $10 \mathrm{~mL}$ of Knop's nutrient solution (ca. 100 spores per mL; Nehira 1988) plus nystatin fungicide $\left(100 \mathrm{U} \mathrm{mL}^{-1}\right)$ solidified with $0.4 \%$ bacteriological agar in Petri dishes (5 cm diameter) (Silva et al. 2006; 2009). Five replicates were used per treatment (under both continuous light and continuous darkness), randomly arranged and then rearranged on a weekly basis. Plastic materials utilized in these experiments were immersed in $70 \%$ ethanol for over $48 \mathrm{~h}$, and then dried under laminar air flow. Petri dishes and nutrient solution were autoclaved for $20 \mathrm{~min}$ at $120^{\circ} \mathrm{C}$, at $1 \mathrm{Kg} \mathrm{cm}^{-2}$. Culture procedures were performed in a laminar air flow chamber in a growth room under controlled conditions (ca. $25^{\circ} \mathrm{C}$, irradiance ca. $20-40 \mu \mathrm{mol} \mathrm{m}^{-2} \mathrm{~s}^{-1}, 12$ $\mathrm{h}$ photoperiod, or continuous darkness - wrapped in black plastic bags).

Daily observations were made (using a dissecting microscope) to detect spore germination and to analyze the early phases of gametophyte development; the study materials were photographed using a digital camera coupled to an optical microscope.

To examine sporeling-type evolution among hornwort genera, we optimized this trait using the parsimony method, employing WinClada version 1.00 .08 software (Nixon 2002) and a simplified phylogenetic tree from Villarreal \& Renner (2012; 2013). Five character states were considered: 1 ) the Leiosporoceros-type, represented by a club-shaped mass of cells; 2) the Anthoceros-type, represented by a columnar mass of cells preceded by a germ tube; 3 ) the NotothylasPhaeoceros-type, represented by a cylindrical/globose mass of cells; 4) the Megaceros-Nothoceros-type, with a large globose 

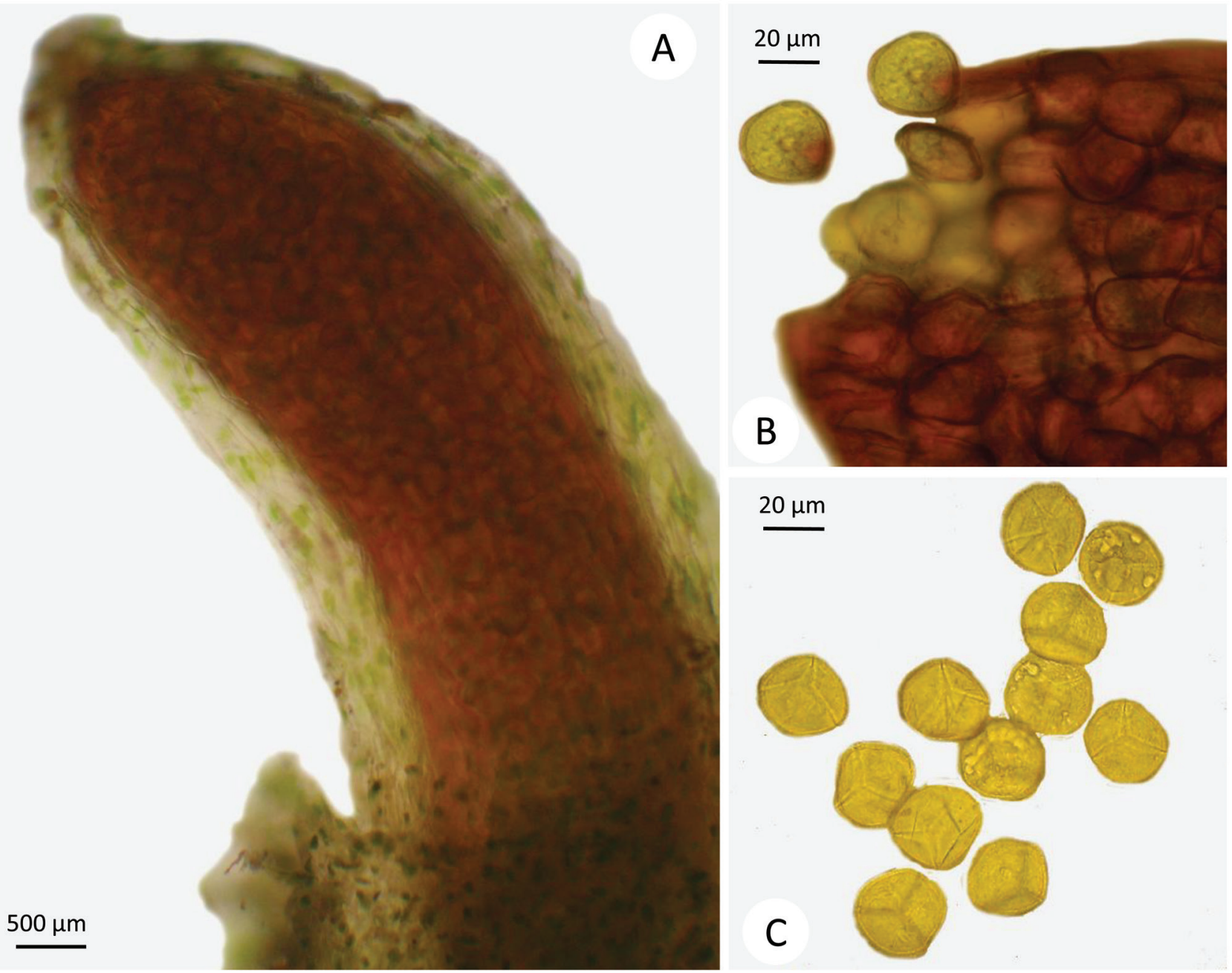

Figure 1. Notothylas vitalii Udar \& Sigh. A - Sporangium inside the involucre; B -Apical region of the sporangium, with no indication of a true dehiscence line; $C$ - Yellow spores with trilete marks.

mass of cells; and, 5) the Nothoceros-Dendroceros-type, which shows endosporic development (Nehira 1983; Menéndez 1988; Herguido \& Ron 1989; Villarreal \& Renzaglia 2006; Villarreal et al. 2012; JC Villarreal unpubl. res.). The sporeling types of Folioceros and Paraphymatoceros are still unknown.

The spores of Notothylas vitalii were observed (using an optical microscope) to be golden colored, unicellular, with smooth surfaces and a trilete scar, and to contain oil droplets (Figs. 1C, 2A). Spore germination occurred after approximately thirty days of laboratory culture, but only when exposed to light. Late germination is common among some hornwort species, such as Phymatoceros bulbiculosus (varying between 11 and 40 days, depending on temperature and photoperiod conditions) (Herguido \& Ron 1989) and Anthoceros punctatus, A. erectus, and Notothylas levieri (10, 24 and 35 days respectively) (Mehra \& Kachroo 1962); in contrast, the spores of $N$. javanica germinated after only two days (Mehra \& Kachroo 1962). A light requirement for germination (i.e., positive photoblastism), combined with the long latent period for spore germination, suggest that $N$. vitalii can establish soil spore banks. This would explain why this species (similar to other hornworts in Brazil) appears in ephemeral and annual populations one or two months after a rainy period and then quickly disappear (O Yano unpubl. res.). Anthoceros agrestis and Phaeoceros carolinianus, for example, develop spore banks in cultivated fields in Switzerland, and their populations are favored by the soil management techniques used for crop cultivation (Bisang 1995; Cailliau \& Price 2007).

Corroborating the spore germination pattern reported for Notothylas orbicularis, N. levieri, and N. javanica (Mehra \& Kachroo 1962; Renzaglia 1978), germination in N. vitalii occurs outside the exospore, with its walls breaking into three or four pieces (Fig. 2B, C); in related taxa such as Phaeoceros, Phymatoceros, and Phaeomegaceros, spore germination also involves exospore rupture into three or four fragments 


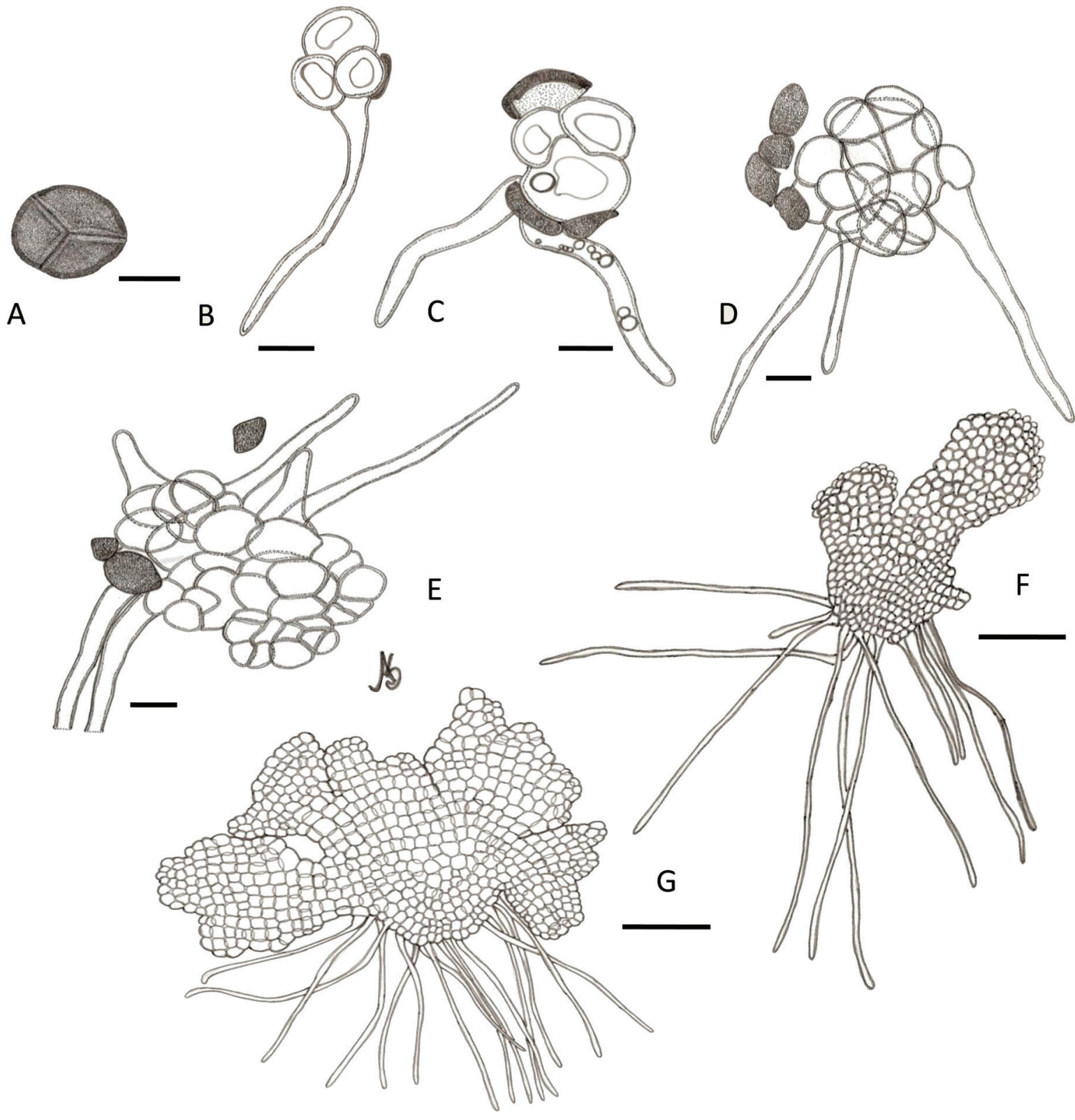

Figure 2. Sporeling development of Notothylas vitalii Udar \& Sigh. A - Spore; B and C - Rupturing the exospore; D and E - Small

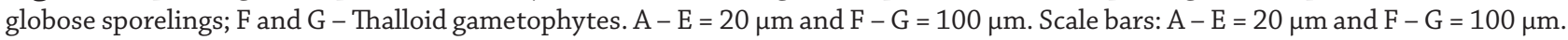

(Nehira 1983; Menéndez 1988; Herguido \& Ron 1989; Villarreal \& Renzaglia 2006). Other genera show irregular exospore rupturing, such as Leiosporoceros, Anthoceros, Nothoceros, and Megaceros, which open through a monolete or a trilete mark (Renzaglia 1978; JC Villarreal unpubl. res.). In the epiphytes Dendroceros spp. and Nothoceros renzagliensis, however, germination is endosporic and intracapsular (ca. five to 25 cells), apparently to protect the sporeling during dry conditions (Menéndez 1988; Schuette \& Renzaglia 2010; Villarreal et al. 2012).
A small globose sporeling develops in $N$. vitalii, with each of its cells having a single large chloroplast (Fig. 2D); although its gametophytes have pyrenoids (Villarreal \& Renner 2012), none were detected in the early stages of sporeling development. The cells continue dividing into several groups of four cells, forming a loose mass, and, subsequently, the thallus. In contrast, species of Notothylas, Phaeoceros erectus (as Anthoceros erectus), and Anthoceros punctatus produce a germ tube that develops into a column of cells that later divides to form a thallus (Mehra \& Kachroo 
1962). The sporeling of $P$. bulbiculosus starts as a globose and loose mass of cells, later becoming a cylindrical columnar structure, with peripheral cells that are larger than its apical cells, which continues to divide and dichotomize the thallus (Herguido \& Ron 1989). In Megaceros tosanus, a primary cell divides continuously to form a globose and compact mass of cells (Nehira 1983; Renzaglia 1978), while in Dendroceros and $N$. renzagliensis the mature spore (still inside the capsule) develops into a compact protonema (Nehira 1983).

The wedge-shaped apical cells of $N$. vitalii eventually divide longitudinally and transversely into smaller cells (Fig. 2E), with subsequent cell divisions producing a thalloid gametophyte (Fig. 2F) whose terminal lobes become flattened over time. This pattern has been observed in many other hornwort species, such as Phaeocerus erectus (as Anthoceros erectus), Notothylas javanica, and Megaceros tosanus (Mehra \& Kachroo 1962; Renzaglia 1978; Nehira 1983). Rosette-like juvenile thalli were observed with $N$. vitalii after ca. fifty days of culture under laboratory conditions (Fig. 2G); the early gametophytes resembled those of $N$. orbicularis (Renzaglia 1978), with a globose multicellular mass formed by wedge-shaped apical cells growing into a rosette-shaped thalloid gametophyte. The sporelings of $N$. vitalii differ from those of $N$. levieri and $N$. javanica (which are globose-cylindrical multicellular clumps that develop into a cylindrical mass of cells) (Mehra
\& Kachroo 1962); the results for $N$. levieri and $N$. javanica should be carefully considered, however, as the authors used only a weak light source to grow the sporelings.

We were not able to infer the possible ancestral sporeling type of the hornworts as there is no information available concerning the sporeling types of some key genera, such as Folioceros. If Folioceros has a sporeling type similar to Leiosporoceros (club-shaped), it would indicate that a clubshaped mass of cells was the ancestral type in hornworts (Fig. 3). We suggest, however, that the Phaeoceros-Notothylastype (a cylindrical/globose mass of cells) appeared in a branch that diverged into three families - Notothyladaceae, Phymatocerotaceae and Dendrocerotaceae. Additional studies will still need to be carried out, however, to confirm the sporeling type of Paraphymatoceros (Notothyladaceae). Finally, it is unknown when large masses of cells and endospory appeared in the other genera of Dendrocerotaceae (Fig. 3) - especially as Villarreal et al. (2012) suggested that endospory arose independently in Nothoceros renzagliensis and in species of Dendroceros. This data shows the imperative of investigating the sporeling types of the missing hornwort genera to fully understand the evolution of that character.

In conclusion, the germination pattern of Notothylas vitalii, an endemic Brazilian species, adds to our knowledge of the Anthocerotophyta. Unfortunately, as discussed by Renzaglia et al. (2007), this group is still the most neglected

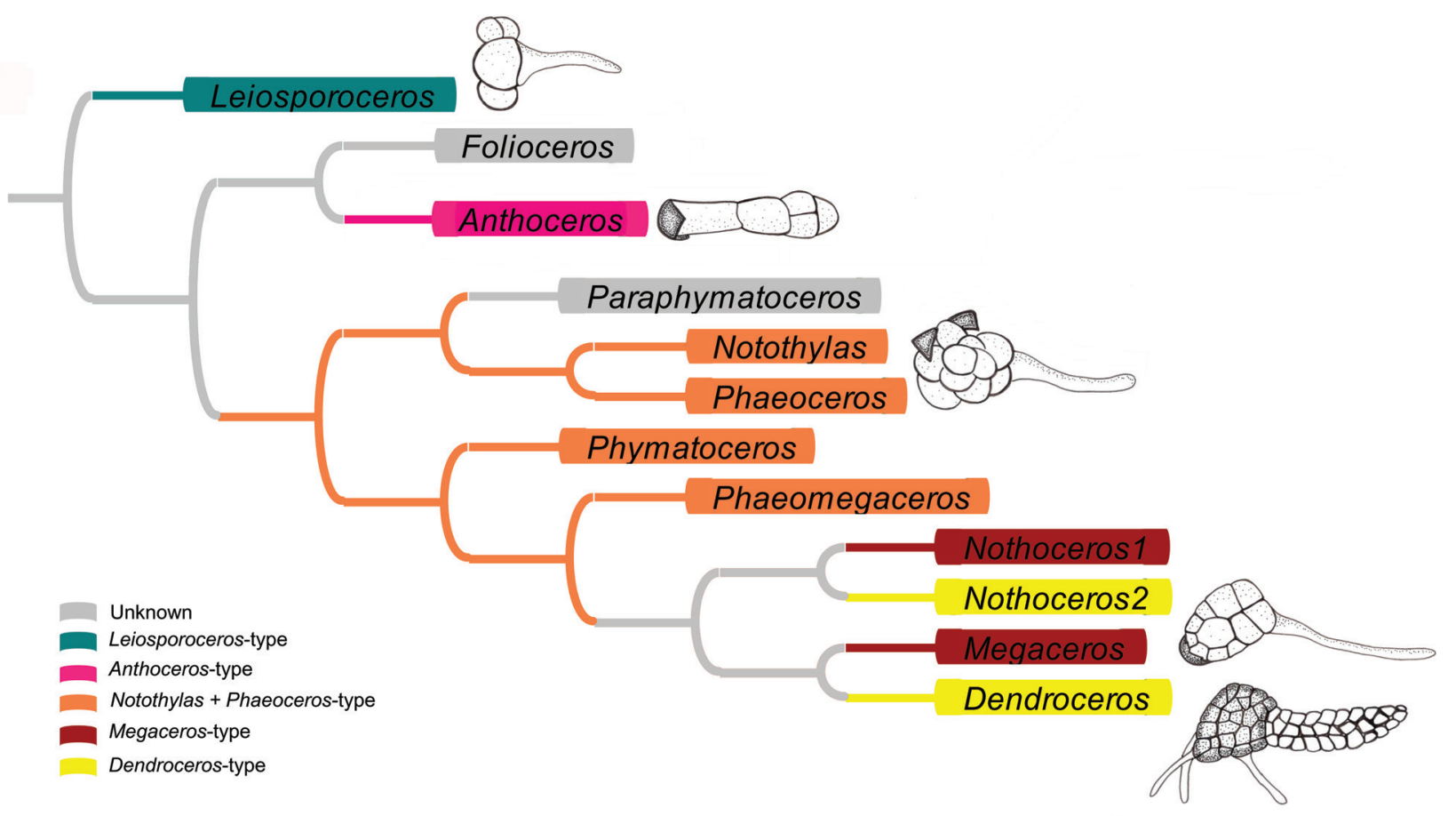

Figure 3. Sporeling types in an optimized hornwort phylogeny, simplified from Villarreal \& Renner (2012; 2013). The Leiosporocerostype, with a club-shaped mass of cells; the Anthoceros-type, with a germ-tube shaped sporeling; the Notothylas-Phaeoceros-type, with a mass of cells; the Nothoceros-Megaceros-type, with a large globose mass of cells; and the Nothoceros-Dendroceros-type, showing endosporic germination. Please see the PDF version for color reference. 
and poorly studied major group of land plants, with few publications focusing on their sporelings. This character is still unknown for some key genera, such as Folioceros and Paraphymatoceros. Supplementary studies on sporeling development will therefore be necessary to further elucidate the evolution and distribution patterns of hornworts, and it will be important to combine morphological and phylogenetic studies to further our understanding of the evolution of this group.

\section{Acknowledgements}

We thank J.C. Villarreal for the critical reading of a previous version of this manuscript, and G.F. PeñalozaBojaca for assistance with the figures.

\section{References}

Bartholomew-Began SE, Crandall-Stotler B. 1994. The sporeling ontogeny of Monoclea gottschei subsp. elongata. The Bryologist 97: 244-252.

Benitez A, Gradstein SR, Prieto M, et al. 2012. Additions to the bryophyte flora of Ecuador 2. Tropical Bryology 34: 99-106.

Bisang I. 1995. The diaspore bank of hornworts (Anthocerotae, Bryophyta) and its role in the maintenance of populations in cultivated fields. Cryptogamica Helvetica 18: 107-116.

Cailliau A, Price MJ. 2007. Hornworts in the agricultural fields of Geneva: new findings, the soil diaspore bank and ex situ soil cultures. Candollea 62: $165-172$

Campbell DH. 1895. The structure \& development of the mosses \& ferns (Archegoniatae). New York, London, Macmillan.

Cargill DC, Renzaglia KS, Villarreal JC, Duff RJ. 2005. Generic concepts within hornworts: historical review, contemporary insights and future directions. Australian Systematic Botany 18: 7-16.

Chantanaorrapint S. 2015. Studies on Thai Anthocerotophyta II. The genus Notothylas (Notothyladaceae). Cryptogamie, Bryologie 36: 251-266.

Duckett JG, Burch J, Fletcher PW, et al. 2004. In vitro cultivation of bryophytes: a review of practicalities, problems, progress and promise. Journal of Bryology 26: 3-20.

Duff RJ, Cargill DC, Villarreal JC, Renzaglia KS. 2004. Phylogenetic relationships of the hornworts based on rbcL sequence data: novel relationships and new insights. Monographs in Systematic Botany from the Missouri Botanical Garden 98: 41-58.

Duff RJ, Villarreal JC, Cargill DC, Renzaglia KS. 2007. Progress and challenges toward developing a phylogeny and classification of the hornworts. The Bryologist 110: 214-243.

Gradstein SR, Costa DP. 2003. The Hepaticae and Anthocerotae of Brazil. Memoirs of The New York Botanical Garden 87: 1-318.

Herguido P, Ron E. 1989. Sobre la germinación de la espora en Phaeoceros bulbiculosus (Brothero) Prosk. Cryptogamie Bryologie Lichénologie 10: 353-359.

Liu S, Wei H, Peng X, Li J. 2016. Spore germination and protonemal development of Dolichomitriopsis diversiformis. Brazilian Archives of Biology and Technology 59: 1-8.

Luna E. 1990. Protonemal development in the Hedwigiaceae (Musci), and its systematic significance. Systematic Botany 15: 192-204.

Martins DV, Bastos CJP, Yano O. 1990. Ocorrência de Notothylas vitalii e Phaeoceros laevis em São Paulo e Bahia, Brasil. Revista Brasileira de Botânica 13: 15-18.

Mehra P, Kachroo P. 1962. Sporeling germination studies in Anthocerotales. The Journal of the Hattori Botanical Laboratory 25: 145-153.

Menéndez GH. 1988. A proposal for a new classification of the genera within the Anthocerotophyta. The Journal of the Hattori Botanical Laboratory 64: 71 - 86.
Mishler BD. 1986. Ontogeny and phylogeny in Tortula (Musci: Pottiaceae). Systematic Botany 11: 189-208.

Nehira K. 1983. Spore germination, protonema development and sporeling development. In: Schuster RM. (ed). New Manual of Bryology. Nichinan, The Hattori Botanical Laboratory. p. 343-379.

Nehira K. 1988. Germination and protonema. In: Glime JM. (ed). Methods in Bryology. Nichinan, The Hattori Botanical Laboratory. p. 113-117.

Nixon KC. 2002. WinClada ver. 1.00.08. Ithaca, Published by the author.

Renzaglia KS. 1978. A comparative morphology and developmental anatomy of the Anthocerotophyta. The Journal of the Hattori Botanical Laboratory 44: 31-90.

Renzaglia KS, Bartholomew SE. 1985. Sporeling development in Fossombronia cristula Aust. with special reference to the apical organization and growth. The Bryologist 88: 337-343.

Renzaglia KS, Schuette S, Duff RJ, et al. 2007. Bryophyte phylogeny: advancing the molecular and morphological frontiers. The Bryologist 110: 179-213.

Renzaglia KS, Villarreal JC, Duff RJ. 2008. News insights into morphology, anatomy, and systematic of hornworts. In: Goffinet B, Shaw AJ (eds). Bryophyte Biology. Cambridge, Cambridge University. p. 139-171.

Schuette S, Renzaglia KS. 2010. Development of multicellular spores in the hornwort genus Dendroceros (Dendrocerotaceae, Anthocerotophyta) and the occurrence of endospory in Bryophytes. Nova Hedwigia 91: 301-316.

Shaw J, Renzaglia K. 2004. Phylogeny and diversification of bryophytes. American Journal of Botany 91: 1557-1581.

Silva ASM, Pôrto KC, Simabukuro EA. 2009. Effect of light and water availability on spore germination and protonemal growth of the Neotropical moss Thamniopsis incurva (Pilotrichaceae). Cryptogamie Bryology 30: 243-257.

Silva, ASM, Simabukuro EA, Pôrto KC. 2006. Morfogênese protonemática de briófitas ocorrentes em Remanescentes de Floresta Atlântica do Estado de Pernambuco, Brasil. Boletim do Instituto de Botânica 18: 213-227.

Söderström L, Hagborg A, Konrat M, et al. 2016. World checklist of hornworts and liverworts. PhytoKeys 59: 1-828.

Stech M, Quandt D, Frey W. 2003. Molecular circumscription of the hornworts (Anthocerotophyta) based on the chloroplast DNA trnLtrnF region. Journal of Plant Research 116: 389-398.

Stieperaere H, Matcham HW. 2007. Notothylas orbicularis (Schwein.) Sull. in D. R. Congo and Uganda, new to Africa and N. javanica (Sande Lac.) Gottsche new to D. R. Congo (Anthocerotophyta, Notothyladaceae). Journal of Bryology 29: 3-6.

Stotler RE, Crandall-Stotler B. 2005. A revised classification of the Anthocerotophyta and a checklist of the hornworts of North America, North of Mexico. The Bryologist 108: 16-26.

Udar R, Singh DK. 1980. An interesting Notothylas from Brasil. Miscellanea Bryologica et Lichenologica 8: 173-178.

Udar R, Singh DK. 1981. Recent concepts in the taxonomy of the genus Notothylas. Contemporary Trends in Plant Sciences 125: 162-174.

Villarreal JC, Campos, LVS, Uribe, JM, Goffinet, B. 2012. Parallel Evolution of Endospory within Hornworts: Nothoceros renzagliensis (Dendrocerotaceae), sp. nov. Systematic Botany 37: 31-37.

Villarreal JC, Renner SS. 2012. Hornwort pyrenoids, carbon-concentrating structures, evolved and were lost at least five times during the last 100 million years. Proceedings of the National Academy of Sciences 109: 18873-18878.

Villarreal JC, Renner SS. 2013. Correlates of monoicy and dioicy in hornworts, the apparent sister group to vascular plants. BMC Evolutionary Biology 13: 239.

Villarreal JC, Renzaglia, KS. 2006. Sporophyte structure in the Neotropical hornwort Phaeomegaceros fimbriatus: implications for phylogeny, taxonomy, and character evolution. International Journal of Plant Sciences 167: 413-427.

Wada K, Hirabayashi Y, Saito W. 1984. Light germination of Anthoceros miyabeanus spores. Botanical Magazine 97: 369-379.

Yano O, Peralta DF, Bordin J. 2011. Antóceros e hepáticas dos Estados de Alagoas, Bahia, Pernambuco e Sergipe, Brasil, depositados no Herbário SP. Hoehnea 38: 429-481. 